\title{
Two new chironomids bearing peculiar morphological features from Japan and China (Diptera: Chironomidae)
}

\author{
Masaru YAMAMOTO, ${ }^{1}$ Nao YAMAMOTO,${ }^{2}$ Hongqu TANG ${ }^{3}$ \\ ${ }^{1}$ 1-6-12, Yoshimi-satomachi, Shimonoseki, Yamaguchi 759-6525, Japan; ${ }^{2}$ KYOUSEI Science Center for Life and Nature, Nara Women's \\ University, Kitauoya-higashimachi, Nara City, Nara Prefecture 630-8506, Japan; ${ }^{3}$ Institute of Groundwater and Earth Science, Jinan \\ University, Guangzhou 510632, China \\ *Corresponding author: qsphn570@ybb.ne.jp
}

\begin{abstract}
A new subgenus, Nothorthocladius, of the genus Orthocladius v. d. Wulp of the subfamily Orthocladiinae and a new genus Yaethauma which bears a superficially resemblance to Collartomyia Goethgebuer, 1948 of the subfamily Chironominae are erected, and the subgeneric and generic diagnoses are provided here. Orthocladius (Nothorthocladius) brevistylus sp. n. is described based on a single male and Yaethauma longiligulata sp. $\mathrm{n}$. is described in both sexes. The former species is characterized from any other orthoclads by having the short gonostylus fused to gonocoxite. The species is treated as a member belonging to the genus Orthocladius based on various morphological features. The latter species is distinguishable from two other members of Collartomyia species by having the antepronotal lobe distinctly narrowed dorsally, the long ligula being sclerotized on the dorsolateral surface along outer margin, and the distinctly bifurcated pulvilli. Furthermore, in the male, the long and spindle-shaped anal point, the short and ovoid gonostylus, the long and distally expanded median appendage, the short and dorsolaterally elongate laterosternite, the plate-like apodeme lobe and the spermatheca bearing sclerotized neck in the female will be sufficiently separated from any described genera clearly.
\end{abstract}

Key words: Orthocladius subgenus, Nothorthocladius new subgenus, Chironominae genus, Yaethauma new genus, new species, Chironomidae.

Received: February 2018. Accepted: May 2018.

This paper was presented at the $20^{\text {th }}$ International Symposium on Chironomidae, Trento, Italy, 2-8 July 2017. Session: Taxonomy and Systematics.

urn:lsid:zoobank.org:pub:EB089868-D7EE-419B-B992-02A5847DD006

urn:lsid:zoobank.org:pub:6A2A126C-A05E-46F6-B523-2A9429D8B7D8

\section{INTRODUCTION}

Two new chironomids bearing peculiar features were collected from Japan and China. One is belonging to Orthocladiinae, and another to Chironominae. In adult males, Orthocladiinae species are characterized by the following combination of characters: i) gonostylus movable and usually folded inward by the reason that it is clearly articulated with gonocoxite, ii) fore tarsomere 1 always shorter than fore tibia, iii) hind tibial comb, when present, consisting of free spiniform setae. On the other hand, Chironominae species bear following characters: i) gonostylus jointed to gonocoxite through membrane or fused to gonocoxite, ii) gonostylus usually unmovable, but in some genera, it can be movable inward (Stictochironomus Kieffer, Nilodosis Kieffer, Shangomyia Sæther et Wang, Xiaomyia Sæther et Wang), iii) fore tarsomere 1 usually longer than fore tibia, iv) mid and hind tibial comb consisting of fused spines.

In 1997, we could get a curious specimen belonging to Orthocladiinae from midland of Honshu, Japan. The specimen is quite different from any other orthoclads in having the rather short gonostylus which is entirely fused to the gonocoxite as showing in the members of the Harnischia-complex of the subfamily Chironominae. This specimen bears a strong resemblance to the members of the genus Orthocladius in many morphological aspects excluding above-mentioned character. Here, we describe the specimen as a new species belonging to a newly erected subgenus of the genus Orthocladius.

In 2002, the first author collected one more curious female chironomid specimen from Iriomote Island, Yaeyama Islands, Okinawa Prefecture, Ryukyus, Japan at the marsh surrounded by the woods in which Barringtonia racemose forms a colony. Recently, we could get the male specimen which is evaluated as the same species based on the peculiar features excluding the sexual difference from Changjiang County, Hainan Island, China. These two specimens each has a characteristic thorax as can be seen in the genus Eurycnemus v. d. Wulp of the subfamily Orthocladiinae. However, it became clear that these specimens are belonging to a member of the subfamily Chironominae based on the features of wing venation, legs and male hypopygium. Two other species bearing such 
characteristic thoracic structure like Eurycnemus were reported from South Africa and Ghana (Amakye and Sæther, 1992; Amakye, 1995). These are Collartomyia hirsuta (Goetghebuer, 1948) and C. discaudata Amakye, 1995, which are belonging to the Subfamily Chironominae. Although the latter species is different from the former in various characters, Amakye (1995) treated them as being congeneric. The present specimens each is distinguishable from two known Collartomyia species by having the following combination of characters; i) ligula long and distinctly sclerotized along its dorsolateral margin of outer side; ii) pulvilli distinctly bilobed, consisting large pad-like outer lobe and slender inner lobe; iii) in male, anal point long, slender and spindle-shaped; iv) gonostylus short and ovoid; v) median appendage long, slender and distally expanded; vi) in female, VIII tergite divided by median longitudinal fissure; vii) IX tergite divided at middle; viii) laterosternite slender and with a small protuberance on its median portion; ix) apodeme lobe well developed and plate-like. Here, we describe these specimens as a new species belonging to a new genus.

\section{METHODS}

The descriptions of coloration were based on dried specimens. The dried specimens removed wings were heated in $5 \% \mathrm{KOH}$ solution, washed in distilled water containing a small quantity of glacial acetic acid, placed in $80 \%$ ethanol for clearing. Then, the head, thorax, legs and abdomen were separated from each other. The head, thorax and abdomen were temporarily mounted in glycerol, in which each part was kept safely to prevent the artificial modification from pressure of coverslip by putting some slivers of broken glass under a coverslip. All drawings were made using an ocular grid and graph paper. The specimens used for descriptions and illustrations were finally mounted permanently on slide in Euparal.

The terminology and measurements mainly follow Sæther (1980). The epandrium, hypandrium, basal median lobe, basal lobe, dorsal appendage, median appendage, ventral appendage and paramere are each used for IX T, IX S, superior volsella, inferior volsella in Orthocladiinae, superior volsella, median volsella, inferior volsella in Chironominae and phallapodeme in the male hypopygial structure (Tokunaga, 1940; Oliver, 1981; Soponis, 1977; Spies et al., 2009), and laterosternite and egg-guide (Wensler \& Rempel 1962) are used for gonocoxite IX and the lobes of gonapophysis VIII of Sæther (1980) in the female genitalia.

Morphological abbreviations used in the text are standard in Chironomidae systematics and can be found in Sæther (1980).

The holotypes are deposited in the Kyushu University Museum (KUM), Fukuoka, Japan, and the paratype is housed in the collection of Jinan University, China.

\section{RESULTS}

\section{Subfamily Orthocladiinae}

\section{Genus Orthocladius v. d. Wulp}

Subgenus Nothorthocladius Yamamoto, Yamamoto et Tang, subgen. $n$.

Type species: Orthocladius (Nothorthocladius) brevistylus sp. $\mathrm{n}$. by present designation.

Etymology: From Greek, nothos, false, and Orthocladius, a genus of Orthocladiinae.

\section{Diagnosis (male imago)}

Head. Eyes bare, with dorsomedial elongation slightly developed. Temporals uniserial. Cornua parallel-sided, well developed.

Thorax. Antepronotal lobe with several lateral antepronotals. Acrostichals absent, dorsocentrals uniserial, several prealars, supraalars absent. Scutellum with setae bi- to triserial.

Wing. Membrane with fine punctuation; anal lobe strongly developed, costa clearly extending, $R_{2+3}$ ending at basal $1 / 3$ between $R_{1}$ and $R_{4+5} ; R_{4+5}$ and costa ending slightly beyond $\mathrm{M}_{3+4} ; \mathrm{Cu}_{1}$ slightly curved; postcubitus and anal vein ending far distal to cubital fork. Squama with many fringed setae.

Legs. Tibial spurs and hind tibial comb normal. Pseudospurs present on tarsomeres 1-2 of mid and hind legs. Sensilla chaetica present on tarsomeres 1 of mid and hind legs. Pulvilli absent.

Hypopygium. Anal point long, robust, gradually tapering to rounded apex, stiff lateral setae directed laterally. Epandrium with few setae on apicolateral portion beside anal point. Sternapodeme slightly convex medially, oral projection weakly developed. Virga small, bifurcated apically. Gonocoxite well developed; basal median lobe absent; dorsal part of median lobe well developed, with ventral part slightly extended laterally. Gonostylus short, rounded apically, completely fuse to gonocoxite in ventral side, crista dorsalis absent.

Remarks. The species is quite different from any other members of the subfamily Orthocladiinae. However, we decided the species is belonging to the genus Orthocladius v. d. Wulp based on the various morphological features diagnosed above. Although sharing many features, the new subgenus can be distinguished from both the subgenera Euorthocladius Thienemann and Mesorthocladius Sæther (Sæther, 2005) by having the gonostylus completely fused to the gonocoxite.

Hereafter, the detailed morphological study about the basic structure of articulation between gonocoxite and gonostyulus should be required by the discovery of the 
new subgenus of Orthocladius and the existence of Stictochironomus, Nilodosis, Shangomyia and Xiaomyia of Chironominae.

\section{Orthocladius (Nothorthocladius) brevistylus Yamamoto, Yamamoto et Tang, sp. $\mathbf{n}$ (Fig. 1)}

Etymology: From Latin, brevis, short, and stylus, referring to the gonostylus of male hypopygium.

\section{Type material}

Holotype. Male (KUM-YN 006), slide mounted in Euparal: Japan, Honshu, Mie Prefecture, Kameyama, 21. ii. 1997, M. Murata.

Male $(\mathrm{n}=1)$

Total length $4.2 \mathrm{~mm}$. Wing $2.5 \mathrm{~mm}$ long, $0.9 \mathrm{~mm}$ wide; wing length / wing width 2.93 .

Coloration. Head brown; antennal pedicel dark brown; mouth parts pale brown. Thorax including antepronotum, scutellum, postnotum and pleura brown; scutal vittae dark brown. Halter pale brown. Abdomen including genitalia brown.

Head (Fig. 1 A-D). Temporal setae 15/16. Antenna lost. Palpomere lengths (in $\mu \mathrm{m}$ ): 44; 60;140; 148; 246; with $0.10,21,19,19$ setae, respectively; third palpomere with 1 sensillum clavatum. Cornua well developed. Clypeus with 28 setae.

Thorax (Fig. 1 E,F). Lateral aptepronotals 6; dporsocentrals 10/11, uniserial; prealars 5, uniserial; supraalar 0 . Scutellum 27 setae, biserial, partially tetraserial.

Wing (Fig. 1G). Anal lobe strongly produced. Costal extension and RM nearly the same in length, ca $100 \mu \mathrm{m}$ long. VR 1.09 . R with $14 / 15$ setae, $R_{1}$ with $1 / 2$ setae, and apical $1 / 4-1 / 3$ of $R_{4+5}$ with $4 / 6$ setae. Brachiolum with 1 median seta; with 10 basal, 3 median and 10 subapical sensilla campaniformia. Squama with 30 fringed setae, partially biserial.

Legs (Fig. $1 \mathrm{H}-\mathrm{J}$ ). Fore, mid and hind coxae with 5, 10, 7 marginal setae, respectively; fore, mid and hind trochanters with 16, 6, 9 marginal setae, respectively. Spur of fore tibia $78 \mu \mathrm{m}$ long; mid tibia with anteroventral spur $30 \mu \mathrm{m}$ and posteroventral spur $38 \mu \mathrm{m}$ long; hind tibia with anteroventral spur $34 \mu \mathrm{m}$ and posteroventral spur $84 \mu \mathrm{m}$ long. Tibial comb composed of 12 spine-like setae. Lengths and proportions of legs as in Tab. 1.
Hypopygium (Fig. 1 K,L). Anal point robust, gradually tapering to rounded apex, $60 \mu \mathrm{m}$ long, $24 \mu \mathrm{m}$ wide at base, and with 11 lateral setae. Hypandrium with 10 setae on its dorsolateral portion. Gonocoxite $168 \mu \mathrm{m}$ long, with dorsal part of basal lobe large, nearly rectangular and with ventral part of basal lobe moderately expanded inwardly which is hidden by dorsal part. Sternapodeme narrow, slightly convex medially, with weakly developed anterolateral projection. Paramere moderately large, triangular, with slender apical elongation. Gonostylus short, obovate, $68 \mu \mathrm{m}$ long, with 2 short somewhat strong setae instead of megaseta on its apical portion, crista dorsalis absent. HR 2.47.

Female and immatures. Unknown.

\section{Subfamily Chironominae}

\section{Genus Yaethauma Yamamoto, Yamamoto et Tang,} gen. $\mathbf{n}$.

Type species: Yaethauma longiligulata sp. $\mathrm{n}$. by present designation.

Etymology: Yae is derived from Yaeyama Islands, Okinawa Prefecture, Ryukyus, Japan, the collecting site of the holotype, and the Greek, thauma, means wonder, referring to the extraordinary elongated and curious shaped scutum.

\section{Diagnosis}

Medium sized species, wing length about $2.1 \mathrm{~mm}$.

Head. Eyes bare, dorsomedial extension nearly parallel-sided. Fontal tubercle absent, coronal suture complete. Temporals biserial, partially triserial. Male antenna with 13 flagellomeres, groove beginning at apex of flagellomere $1,2^{\text {nd }}$ to $4^{\text {th }}$ flagellomeres with paired long sensilla basiconica, ultimate flagellomere with 5 long sensilla basiconica on subapical portion. Female antenna with 6 flagellomeres, $2^{\text {nd }}$ to $5^{\text {th }}$ flagellomeres each with paired long sensilla basiconica. Ultimate flagellomere with several subapical long setae and several long sensilla basiconica. Cibarial pump with short but distinct parallelsided cornua. Tentorium simple, slightly wider at middle in lateral aspect. Palp normal, 5-segmemnted. Labella with prementum lacking sclerotized base. Ligula well developed, long, distinctly sclerotized on dorsolateral surface along outer margin.

Tab. 1. Lengths (in $\mu \mathrm{m}$ ) and proportions of legs of Orthocladius (Nothorthocladius) brevistyulus sp. n., male ( $\mathrm{n}=1$ ).

\begin{tabular}{|c|c|c|c|c|c|c|c|c|c|c|}
\hline & $\mathrm{fe}$ & ti & ta1 & ta2 & ta 3 & $\operatorname{ta} 4$ & $\operatorname{ta} 5$ & LR & BV & SV \\
\hline p1 & 960 & 1080 & 840 & 540 & 360 & 220 & 160 & 0.78 & 2.25 & 2.43 \\
\hline $\mathrm{p} 2$ & 1040 & 1000 & 520 & 340 & 240 & 140 & 140 & 0.52 & 2.98 & 3.92 \\
\hline p3 & 1120 & 1200 & 700 & 420 & 320 & 180 & 160 & 0.58 & 2.8 & 3.31 \\
\hline
\end{tabular}



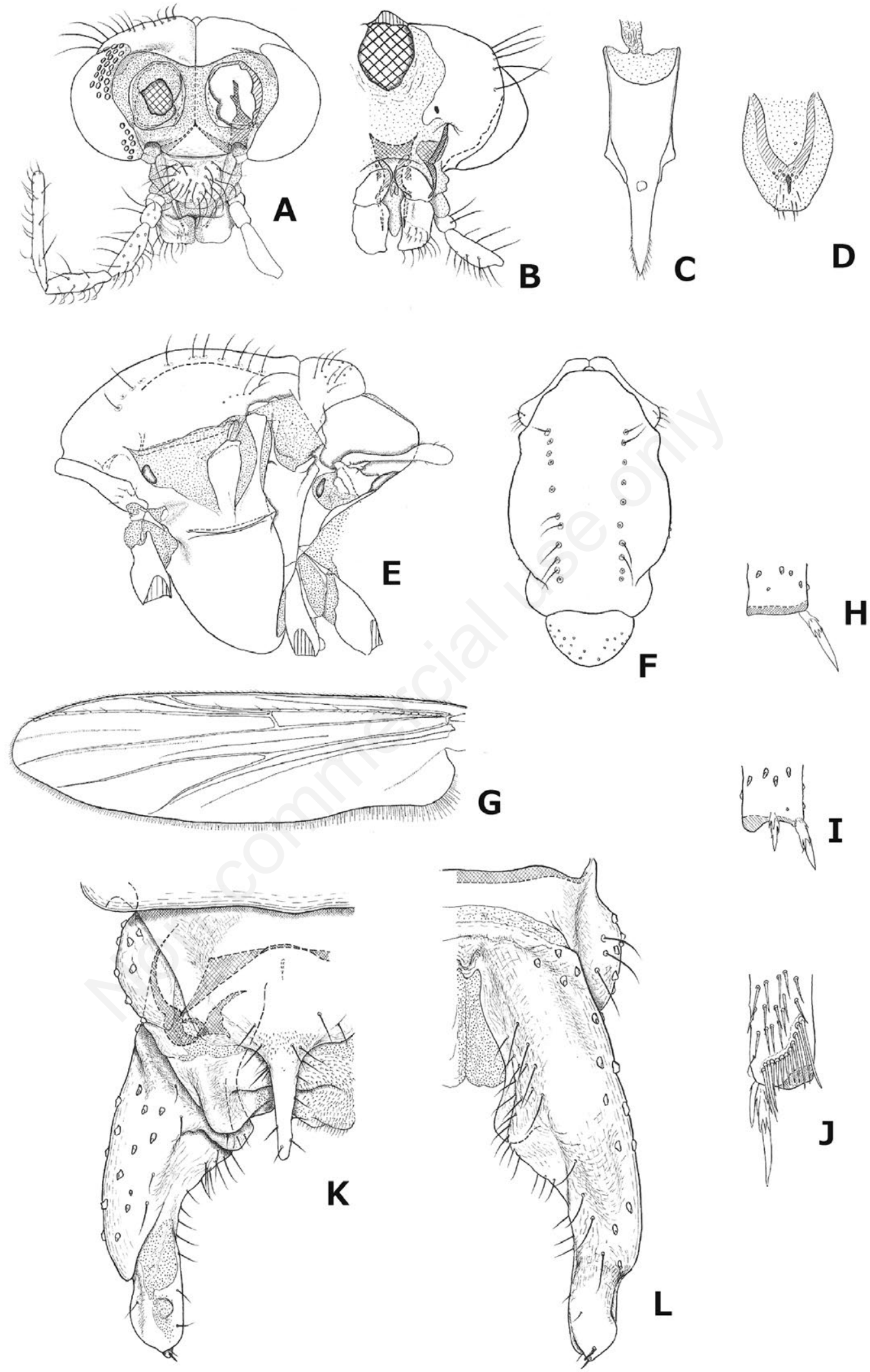

Fig. 1. Orthocladius (Nothorthocladius) brevistyulus sp. n., male (holotype). A) head, frontal view; B) head, caudal view; C) cibarial pump, dorsal view; D) posterior surface of epipharynx; E) thorax, lateral view; F) antepronotum, scutum and scutellum, dorsal view; G) wing; H) apex of fore tibia; I) apex of mid tibia; J) apex of hind tibia; K) hypopygium, dorsal view; L) hypopygium, ventral view. 
Thorax. Antepronotal lobe narrowed dorsally, widely separated medially. Scutum producing forward and tapering to truncated apex in dorsal view, with coneshaped tip in lateral aspect, and with paired depressions at near apex. Acrostichals numerous, biserial, beginning near antepronotum, reaching to anterior $1 / 2$ of scutum; dorsocentrals strong, numerous, triserial to multiserial; prealars irregularly triserial; scutellars irregularly triserial.

Wing. Membrane bare, with fine but distinct punctuation of microtrichia; anal lobe moderately developed. Costa ending at wing tip; $\mathrm{R}_{2+3}$, running and ending close to $R_{1}$, obscure in male, not observable in female. $R, R_{1}$ and $R_{4+5}$ setose. Squama with fringed setae.

Legs. Fore tibial scale triangular to oval, bearing moderate, nearly straight spur. Mid and hind tibia with closely approximated combs, anterolateral one without spur and posterolateral one with elongate spur. Sensilla chaetica and pseudospur absent. Pretarsus with linearlanceolate transparent thin blade at middle ventrally. Pulvili consisting large pad-like outer lobe and slender, twig-like inner lobe.

Abdomen. Tergites and sternites densely covered with long setae.

Male hypopygium. Tergite VIII clearly tapered basally. Epandrium without anal tergite bands, with median oval elevation bearing many long setae. Anal point long, slender, spindle-shaped. Hypandrium with some setae on dorsolaterally. Sternapodeme narrow, without oral projection. Paramere long, slender and strongly sclerotized simple plate. Gonostylus short, ovoid. Dorsal appendage horn-shaped, hocked ventrolaterally at apex, with microtrichiose base bearing some long setae. Median appendage slender, long, extending beyond the tip of anal point, expanded apical $1 / 2$, with several long setae on subapical portion of inner margin. Ventral appendage slender, parallel-sided, slightly shorter than anal point, subapical protuberance with long seta and more than 10 setae on dorsal side of distal 1/3.

Female genitalia. Tergite VIII divided by longitudinal furrow at middle. Tergite IX short, strongly sclerotized along anterior margin, divided into two setose elevations by median depression; laterosternite short and elongated dorsolaterally, along lateral margin of tergite IX, with small ventrolateral protuberance bearing apical seta. Segment X large, swelled, with many setae. Cercus normal, quadrate in shape; postgenital plate triangular, and weakly sclerotized. Egg-guide divided into large dorsomedian lobe and lanceolate ventrolateral lobe. Apodeme lobe large, plate-like. Spermatheca spherical, with sclerotized neck. Spermathecal duct short and slightly bent, with common opening. Labium with microtrichia at tip.

Taxonomic remarks. The new genus bears a strong resemblance to the genus Collartomyia Goetghebuer especially in having the scutum cone-like projecting forwards, overreaching antepronotum, with depression at angular apex of corn. Furthermore, the thoracic chaetotaxy pattern and the feature of the wing venation are almost the same as those of Collartomyia. Two species of the genus Collartomyia are known from South Africa and Ghana, that is, C. hirsuta (Goetghebuer) and $C$. discaudata Amakye. The former species is distinct from the latter by having the following characters: 3 -segmented maxillary palp instead of 5-segmented one, marked wing, tibial scale of fore tibia bearing distinct subapical spur, fused tibial combs. The latter species is distinct from the former by having normal maxillary palp, unmarked wing, separate tibial combs with single spur, pseudospurs present on tatrsomeres 1-2 of mid and hind legs, epandrium without anal point and bilobed dorsal appendage in the male, and well developed ventrolateral lobe and pointed postgenital plate in the female genitalia (Amakye, 1995). Although these two species are different from each other in various characters, Amakye (1995) treated them as being congeneric by the reason of sharing the anteriorly tapered VIII tergite in the male and has no data about the immature stages in $C$. discaudata.

The new genus is clearly separable form both two Collartomyia species by having the following combination of characters: pretarsus with distinctly bilobed pulvilli, consisting large pad-like outer lobe and slender inner lobe; in the male, epandrium with long and slender spindle-shaped anal point, gonocoxite with long median appendage, gonostylus short, ovoid; in the female, spermatheca with sclerotized neck, tergite IX rather short and distinctly divided in the middle, laterosternite short and elongated dorsolaterally and along the lateral margin of tergite IX, with small ventrolateral protuberance bearing apical seta and apodeme lobe large, plate like. Although the new genus somewhat resembles $C$. discaudata in having the normally developed maxillary palp, the structure of tibial combs, the gonocoxapodeme gradually rounded anteriorly and well-developed ventrolateral lobe of egg-guide, the genus is clearly separable from the latter by the characters mentioned above.

In the revision of the genus Beardius Reiss et Sublette, Pinho et al. (2013) gave the new idea for interpreting the volsellae (appendages) on the gonocoxite. In their paper, Beardius phoenix has four pairs of volsellae (appendages) on the gonocoxite. These are interpreted as follows; the dorsal one is treated as superior volsella (dorsal appendage), the appendage which is situated at the basal portion of the superior volsella as median volsella (median appendage), the outermost one which is situated immediately below the superior volsella as the inferior volsella (ventral appendage), and the innermost one as a projection of inferior volsella. The new genus Yaethauma 
is superficially resemblance to $B$. phoenix in having the similar arrangement of appendages on the gonocoxite. In the new genus, we interpret the outermost one which is immediately below the dorsal appendage as the median appendage (median volsella), although it is situated more distal comparing with the normal position, by reason of lying on the ventral side of the basal lobe of dorsal appendage (superior volsella), and the innermost one as the ventral appendage (inferior volsella).

Amakye and Sæther (1992) and Amakye (1995) pointed out that the anteriorly tapering tergite VIII is likely to be a synapomorphic character for Collartomyia and Polypedilum Kieffer. This feature also is recognized in Oukuriella epleri Messias and Fittkau 1997, O. pesae Fusari et al. 2009, O. digita Fusari et al., 2013, O. rimamplusa Fusari et al. 2013 and the new genus. Furthermore, O. oliveirai Messias et Fittkau 1997, Clauditendipes Andersen et al. 2017 and Sigmoitendipes Andersen et al. 2017 each has a VIII tergite weakly tapering anteriorly. The spermatheca bearing a sclerotized neck, which is also considered as a synapomorphous character for Apedilum Townes, Zavreliella Kieffer, Oukuriella Epler and Yaeprimus Sasa et Suzuki (Epler, 1988, 1996; Yamamoto and Yamamoto, 2011), is shared by the new genus Yaethauma. Although these characters are important for inferring the phylogenetic relationship, we keep a prudent attitude to recognize each of them as the synapomorphous character for Collaromyia, Polypedilum, Yaethauma, Oukuriella, Clauditendipes, Sigmoitendipes. In the hypopygial structure of $C$. discaudata and the members of Oukuriella can recognize the following similarities such as the bifurcated dorsal appendage and lack of the anal point. Furthermore, the species shares such character as the subapical protuberance of ventral appendage bearing a long seta with $O$. epleri and $O$. minimawe Fusari et al., 2013. Amakye (1995) stated that the peculiar thorax with a strongly projecting scutum with an apical notch combined with an unreduced antepronotum appear to be a unique synapomorphy for $C$. hirsuta and $C$. discaudata. The character state also is shared by the new genus. It could be a reasonable interpretation regarding the Amakye's statement (1995).

Yaethauma longiligulata Yamamoto, Yamamoto et Tang, sp. n. (Figs. 2-5)

\section{Type material}

Holotype. Female (KUM-YN 007), slide mounted in Euparal: Japan, Ryukyus, Okinawa Prefecture, Yaeyama Islands, Iriomote Island, Funaura, 19. xi. 2001, sweep net by M. Yamamoto.

Paratype. Male (JNU160424009), slide mounted in Euparal: China, Hainan province, Changjiang County,
Bawangling National Nature Reserve, a stream across an unnamed cement road to the field station of Nancha River, $19^{\circ} 06.533^{\prime} \mathrm{N}, 109^{\circ} 11.987^{\prime} \mathrm{E}, 17$. iv. 2016 , light trap by Hongqu Tang.

Etymology: From Latin longus, long, and ligulatus, tang, referring to the long ligula of mouthpart.

Female $(\mathrm{n}=1)$.

Total length $4.3 \mathrm{~mm}$. Wing $2.1 \mathrm{~mm}$ long; $0.7 \mathrm{~mm}$ wide; wing length / wing width 3.18.

Coloration. Body including head and legs predominantly dark brown; scutellum, posterior $3 / 4$ of postnotum pale; middle portion of all tibiae and basal $1 / 3$ to $1 / 4$ of all tarsi pale; halter yellowish brown; posterior $1 / 4$ of $1^{\text {st }}$ to $6^{\text {th }}$ abdominal terga each with silvery pollen band. Wing tinged with brown.

Head (Figs. 3A-G). AR 0.25. Antennal flagellomere lengths (in $\mu \mathrm{m}$ ): $112,100,104,100,96,128$. First to $6^{\text {th }}$ flagellomeres with $8 / 11,8 / 10,9,7 / 9,5 / 6$ setae, respectively. First to $5^{\text {th }}$ palpomere lengths $(\mu \mathrm{m}) ; 36,72$, $138,168,279$; and the palpomeres with 1, 9/12, 23, 30, 12 setae, respectively. Temporal setae 16 , clypeus with 45 setae. Cibarial pump $140 \mu \mathrm{m}$ long, labial lonchus $160 \mu \mathrm{m}$ long. Tentorium $135 \mu \mathrm{m}$ long. Ligula $48 \mu \mathrm{m}$ long. Prementum with 2 setae.

Thorax (Figs. 3H-K). Antepronotum bare. Dorsocentals 78, triserial to tetraserial; prealars 19, biserial to triserial; acrostichals 39, biserial. Scutellum with 36 , irregularly triserial.

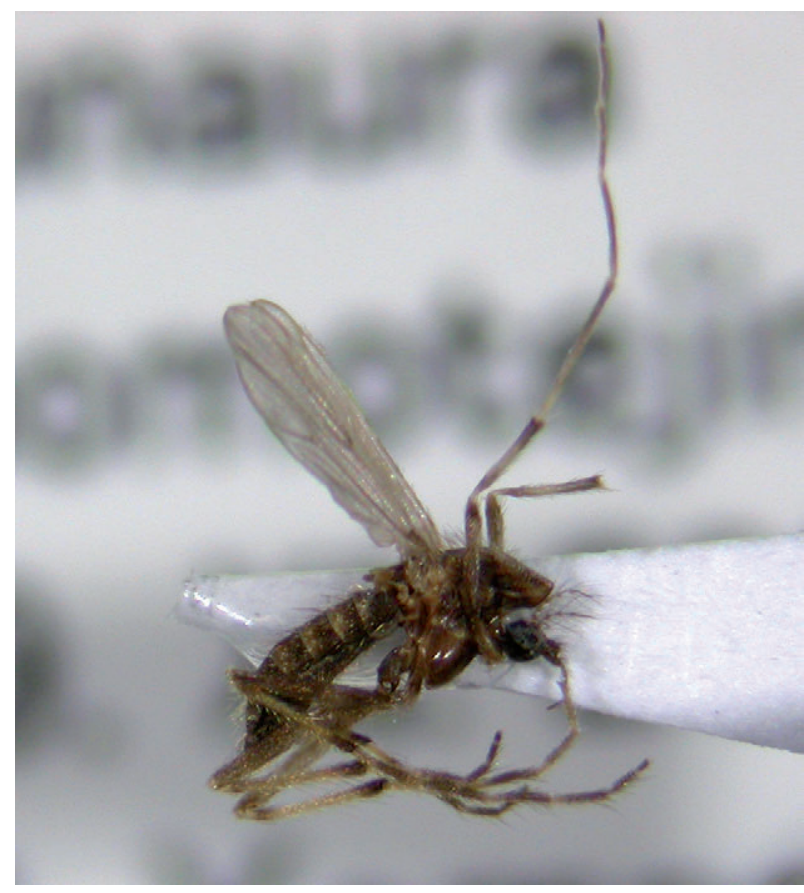

Fig. 2. Yaethauma longiligulata sp. n., female (holotype). 
Wing (Fig. 4A). VR 1.28. R, $\mathrm{R}_{1}$ and $\mathrm{R}_{4+5}$ with 27 , 64, 114 setae, respectively. Brachiolum with 1 seta medially, with 11 basal, 3 median, and 13 subapical sensilla campaniformia. Squama with 30 fringed setae.

Legs (Figs. 4B-G). Scale of foretibia $42 \mu \mathrm{m}$ long, including $28 \mu \mathrm{m}$ long apical spur. Spur on middle tibia
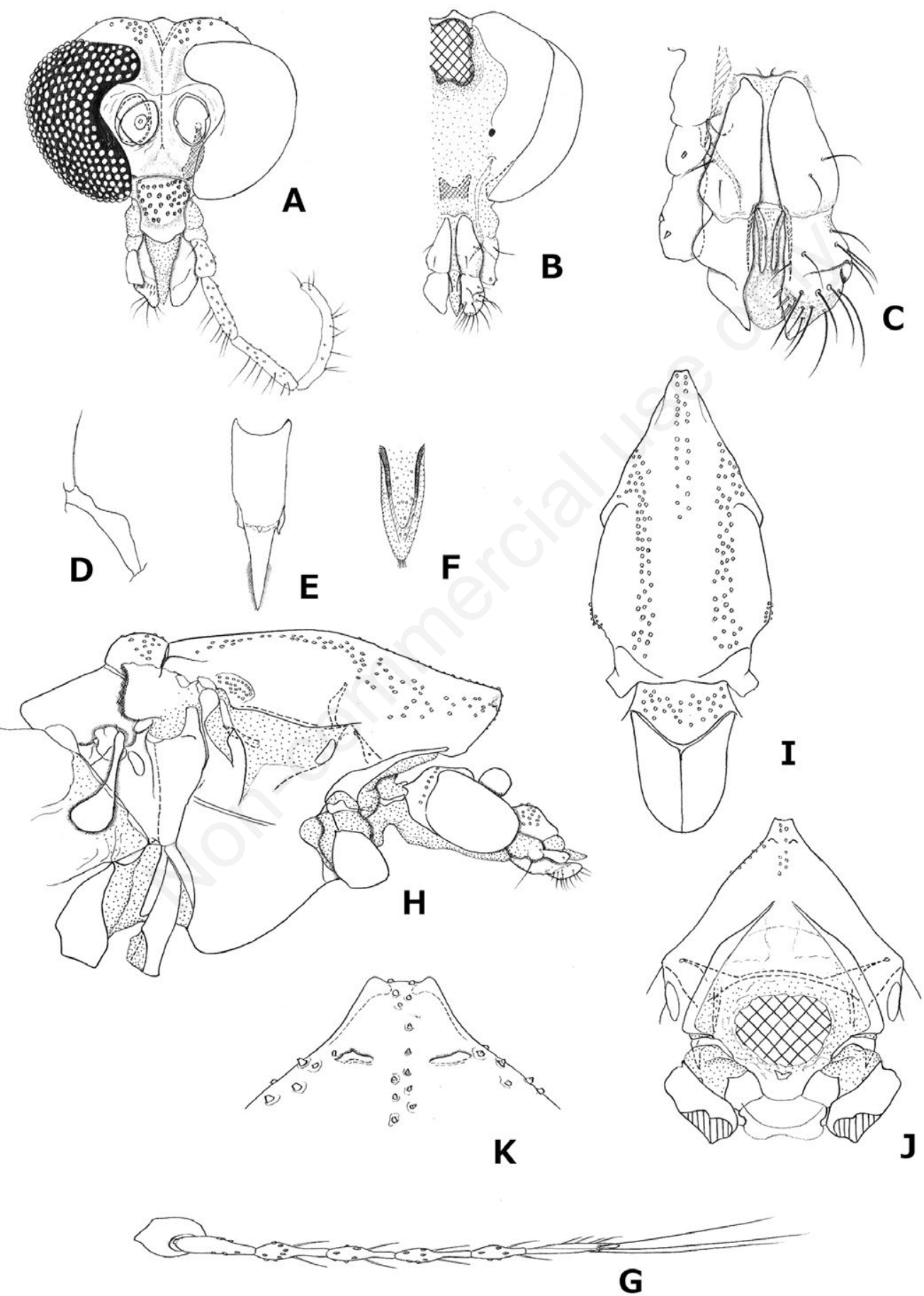

Fig. 3. Yaethauma longiligulata sp. n., female (holotype). A) Head, frontal view; B) head caudal view; C) labella, caudal view; D) tentorium, lateral view; E) cibarial pump, dorsal view; F) posterior surface of epipharynx; G) antenna; H) thorax and head, lateral view; I) thorax, dorsal view; J) thorax, ventrolateral view; K) anterior portion of scutum, ventrolateral view. 
$76 \mu \mathrm{m}$ long, including $44 \mu \mathrm{m}$ long comb, anterolateral comb (unspurred comb) $40 \mu \mathrm{m}$ long, spur on hind tibia $88 \mu \mathrm{m}$ long including $44 \mu \mathrm{m}$ long comb, anterolateral comb (unspurred comb) $40 \mu \mathrm{m}$ long. Fore, mid and hind coxae with 6, 17, 9 marginal setae, respectively. Fore, mid and hind trochanters with 18, 16, 16 setae,
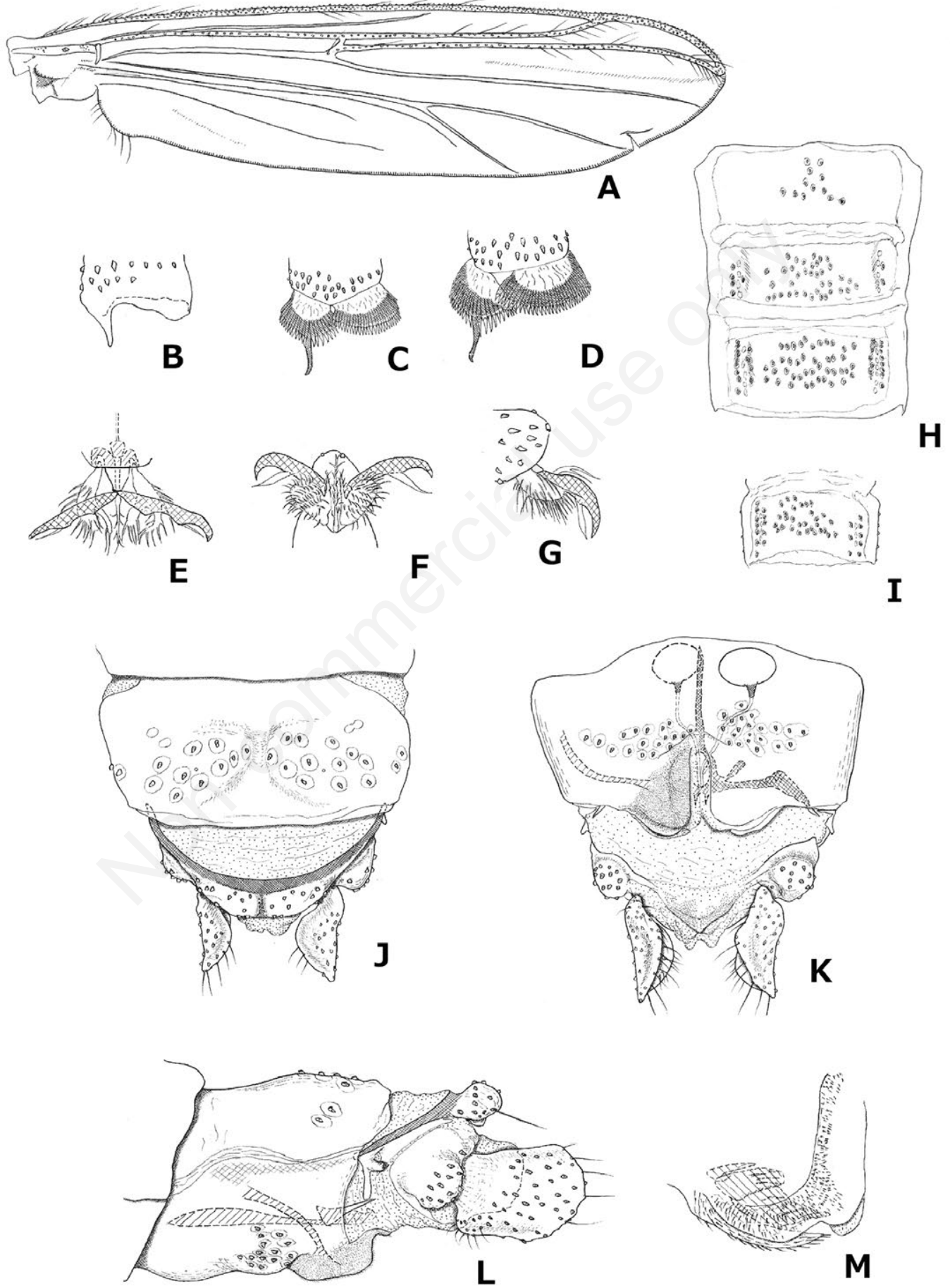

Fig. 4. Yaethauma longiligulata sp. n., female (holotype). A) Wing; B) apex of fore tibia; C) apex of mid tibia; D) apex of hind tibia; H) abdominal tergites I to III, dorsal view; I) abdominal tergite VII, ventral view; J) genitalia, dorsal view; K) genitalia, ventral view; L) genitalia lateral view; M) egg-guide, ventral view. 
respectively. Lengths $(\mu \mathrm{m})$ and proportions of legs as in Tab. 2 .

Abdomen (Figs. 4H,I). Tergites densely covered with long setae.

Genitalia (Figs. 4J-M). Ninth tergite with 13 or 14 setae on each elevation. Laterosternite with 1 seta on ventrolateral protuberance. Segment X with 20/21 setae. Cercus $176 \mu \mathrm{m}$ long, $136 \mu \mathrm{m}$ wide. Notum $148 \mu \mathrm{m}$ long.

Male $(\mathrm{n}=1)$.

Total length $3.8 \mathrm{~mm}$. Wing $2.1 \mathrm{~mm}$ long; $0.7 \mathrm{~mm}$ wide; wing length / wing width 3.12 .

Coloration. As in female.

Head (Figs. 5A,B). AR 0.61. First of $5^{\text {th }}$ palpomere lengths $(\mu \mathrm{m}) ; 44,92,140,180,248$; and the palpomeres with $1,12,24,39,11$ setae, respectively. Third palpomere with 2 sensilla clavata. Temporal setae 18, clypeus with 52 setae. Cibarial pump $156 \mu \mathrm{m}$ long, labial lonchus 140 $\mu \mathrm{m}$ long. Tentorium $134 \mu \mathrm{m}$ long. Ligula $36 \mu \mathrm{m}$ long. Prementum without setae.

Thorax (Fig. 5C). Antepronotum bare. Dorsocentals 70 , triserial to tetraserial; prealars 17 , biserial to triserial; acrostichals 38 , biserial. Scutellum with 46 , irregularly triserial.

Wing (Fig. 5D). VR 3.12. $R, R_{1}$ and $R_{4+5}$ with 38 , 51, 74 setae, respectively. Brachiolum with 1 seta medially, with 11 basal, 3 median, and 13/14 subapical sensilla campaniformia. Squama with 35 fringed setae.

Legs (Fig. 5E). Scale of foretibia $44 \mu \mathrm{m}$ long, including $32 \mu \mathrm{m}$ long apical spur. Spur on middle tibia 73 $\mu \mathrm{m}$ long, including $40 \mu \mathrm{m}$ long comb, anterolateral comb (unspurred comb) $32 \mu \mathrm{m}$ long, spur on hind tibia $76 \mu \mathrm{m}$ long including $44 \mu \mathrm{m}$ long comb, anterolateral comb (unspurred comb) $32 \mu \mathrm{m}$ long. Fore, mid and hind coxae with 7, 18, 4 marginal setae, respectively, mid coxal setae biserially arranged. Fore, mid and hind trochanters with $16,12,16$ setae, respectively, partial biserial. Lengths $(\mu \mathrm{m})$ and proportions of legs as in Tab. 3.
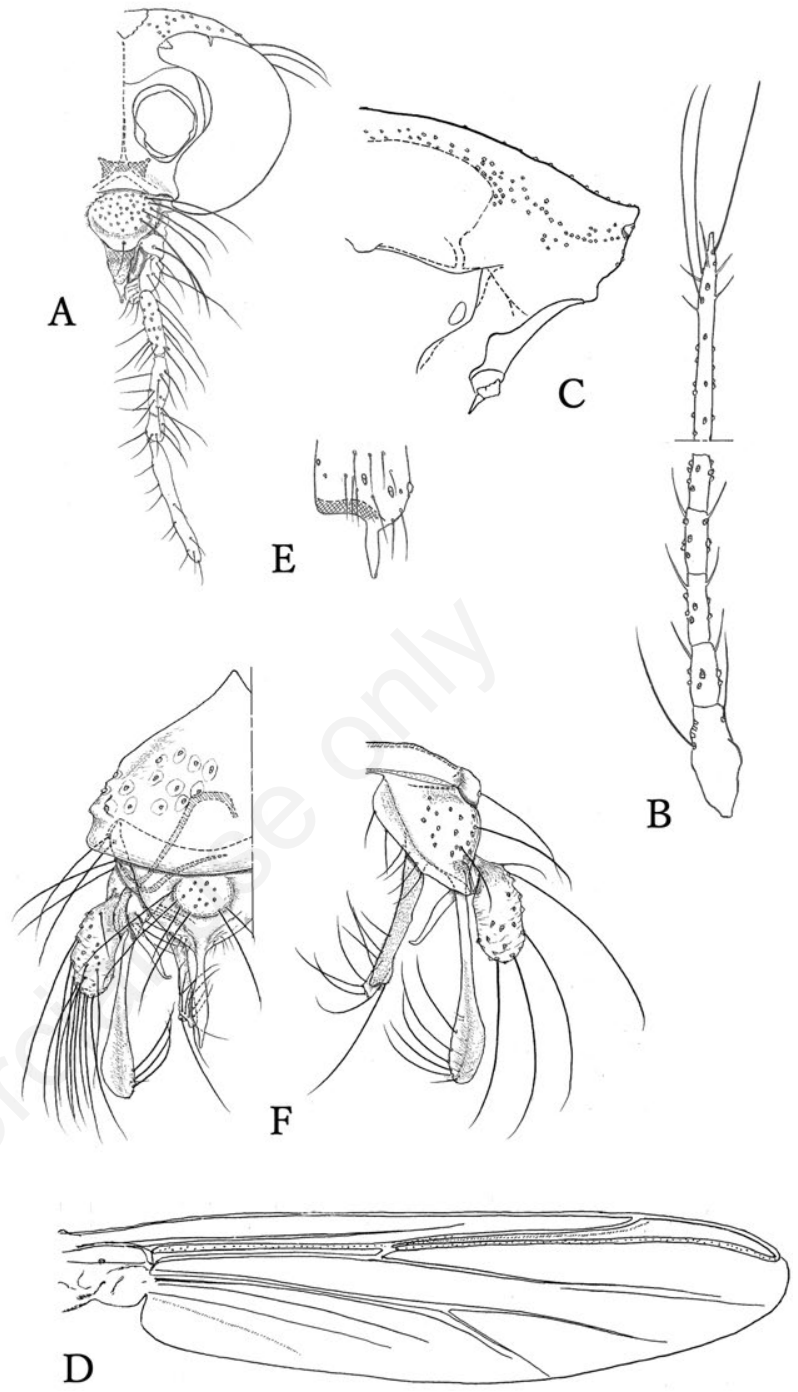

Fig. 5. Yaethauma longiligulata sp. n., male (paratype). A) Head, frontal view; B) antenna; C) thorax, anterior part, lateral view; D) wing; E) apex of fore tibia; F) hypopygium, dorsal view to the left, ventral view to the right.

Tab. 2. Lengths (in $\mu \mathrm{m}$ ) and proportions of legs of Yaethauma longiligulata sp. $\mathrm{n}$., female ( $\mathrm{n}=1)$.

\begin{tabular}{lcccccccccccc} 
& $\mathrm{fe}$ & $\mathrm{ti}$ & $\mathrm{ta1}$ & $\mathrm{ta2}$ & $\mathrm{ta3}$ & $\mathrm{ta}$ & $\mathrm{ta5}$ & $\mathrm{LR}$ & $\mathrm{BV}$ & SV \\
$\mathrm{p} 1$ & 1200 & 820 & 1160 & 740 & 500 & 440 & 220 & 1.41 & 1.67 & 1.74 \\
\hline $\mathrm{p} 2$ & 1340 & 1020 & 560 & 380 & 300 & 200 & 100 & 0.55 & 2.98 & 4.21 \\
\hline p3 & 1420 & 1100 & 840 & 480 & 440 & 280 & 140 & 0.76 & 2.51 & 2.86 \\
\hline
\end{tabular}

Tab. 3. Lengths (in $\mu \mathrm{m}$ ) and proportions of legs of Yaethauma longiligulata sp. $\mathrm{n}$., male $(\mathrm{n}=1)$.

\begin{tabular}{rcccccccccccc} 
& $\mathrm{fe}$ & $\mathrm{ti}$ & $\mathrm{ta1}$ & $\mathrm{ta2}$ & $\mathrm{ta3}$ & $\mathrm{ta4}$ & $\mathrm{ta5}$ & $\mathrm{LR}$ & $\mathrm{BV}$ & $\mathrm{SV}$ \\
$\mathrm{p} 1$ & 1160 & 820 & 1140 & 760 & 520 & 480 & 240 & 1.39 & 1.56 & 1.72 \\
\hline p2 & 1280 & 1020 & 520 & 360 & 280 & 200 & 100 & 0.51 & 3 & 4.42 \\
\hline p3 & 1360 & 1080 & 800 & 500 & 420 & 240 & 128 & 0.74 & 2.52 & 3.05
\end{tabular}


Hypopygium (Fig. 5F). Tergites densely covered with long setae. Epandrium with median oval elevation bearing 23 long setae. Anal point $140 \mu \mathrm{m}$ long, $16 \mu \mathrm{m}$ wide at base, with 14-15 fine setae on each side at base. Hypandrium with $3 / 4$ setae on its dorsolateral portion. Gonocoxite $41 \mu \mathrm{m}$ long, with 6 setae on its inner margin, dorsal appendage $84 \mu \mathrm{m}$ long and with basal lobe bearing 6 setae. Ventral appendage $208 \mu \mathrm{m}$ long, $20 \mu \mathrm{m}$ long wide at base, with 17 setae on subapical portion. Median appendage $252 \mu \mathrm{m}$ long, $12 \mu \mathrm{m}$ wide at base, $44 \mu \mathrm{m}$ wide at subapical expanded portion, with 5/6 long setae on subapical portion of inner margin, and with short apical seta. Gonostylus $144 \mu \mathrm{m}$ long, $56 \mu \mathrm{m}$ wide. HR 1.14.

Pupa and larva unknown.

\section{ACKNOWLEGEMENTS}

We thank to Dr. P. Ashe, Dublin, Ireland, for valuable suggestions about the new genus. We wish to express our thanks to Dr. P. Cranston, Australian National University, Ecology and Genetics, Canberra, Australia, and Dr. T. Ekrem, Norwegian University of Science and Technology, NTNU University Museum, Norway, for their important advice. We also thank Dr. N. Hamada, Coordenação de Biodiversidade, Instituto Nacional de Pesquisas da Amazôniafor, Brazil, for references.

\section{REFERENCES}

Amakye JS, Sæther OA, 1992. The immatures and imagines of Afrotropical species Microtendipes lentiginosus Freeman and Collartomyia hirsuta Goethebuer (Diptera: Chironomidae). Entomol. Scand. 23:429-442.

Amakye JS, 1995. Collartomyia discaudata, spec. nov. from Ghana, with an emendation of the genus. Spixiana 18:271-275.

Andersen T, Mendes HF, Pinho LV, 2017. Two new Neotropical Chironominae genera (Diptera: Chironomidae). CHIRONOMUS J. Chiron. Res. 30:26-54.

Epler JH, 1988. A reconsideration of the genus Apedilum Townes, 1945 (Diptera: Chironomidae: Chironominae). Spixiana Suppl. 14:105-116.
Epler JH, 1996. New species of Oukuriella (Diptera: Chironomidae) from Costa Rica. Hydrobiologia 318:3-11.

Fusari LM, Roque FO, Hamada N, 2009. Oukuriella pesae, a new species of sponge-dwelling chironomid (Insecta: Diptera) from Amazonia, Brazil. Zootaxa 2146:61-68.

Fusari LM, Roque FO, Hamada N, 2013. Systematics of Oukuriella Epler, 1986 including a revision of the species associated with freshwater sponges. Insect. Syst. Evol. 45:117-157.

Messias MC, Fittkau EJ, 1997. Two new species of the Neotropical genus Oukuriella Epler, 1986 (Insecta, Diptera, Chironomidae). Spixiana 20:255-260.

Oliver DR, 1981. Chironomidae, p. 423-458. In: McAlpine JF, Peterson BV, Shewell GE, Teskey HJ, Vockeroth JR, Wood DM (eds.), Manual of Nearctic Diptera. 1. Research Branch Agriculture Canada Monograph.

Pinho LC, Mendes HF, Andersen T, 1913. Revision of Beardius Reiss et Sublette, 1985 (Diptera: Chironomidae), with the description of twenty new species. Zootaxa 3742:1-78.

Sæther OA, 1980. Glossary of chironomid morphology terminology (Diptera: Chironomidae). Entomol. Scand. Suppl. 14:1-51.

Sæther OA, 2005. A new subgenus and new species of Orthocladius van der Wulp, with a phylogenetic evaluation of the validity of the subgenera of the genus (Diptera: Chironomidae). Zootaxa 974:1-56.

Soponis AR, 1977. A revision of the Nearctic species of Orthocladius (Orthocladius) van der Wulp (Diptera: Chironomidae). Mem. Entomol. Soc. Can. 102:1-187.

Spies M, Andersen T, Epler JH, Watson CN, 2009. Chironomidae (non-biting midges), p. 437-480. In: Brown BV, Borkent A, Cumming JM, Wood DM, Woodley NE, Zuumbado (eds), Manual of Central American Diptera. 1. NRC Research Press, Ottawa.

Tokunaga M, 1940. Chironomidae from Japan (Diptera), XII New or little-known Ceratopogonidae and Chironomidae. Philipp. J. Sci. 72: 255-311.

Wensler RJD, Rempel JG, 1962. The morphology of the male and female reproductive systems of the midge, Chironomus plumosus L. Can. J. Zool. 40: 199-227.

Yamamoto M, Yamamoto N, 2011. A review of Yaeprimus isigaabeus Sasa et Suzuki, 2000 (Diptera: Chironomidae), with taxonomic notes on the genera distributed in Yaeyama Island, p. 224-239. Proceedings 17th Int. Symp. on Chironomidae, Tianjin. Nankai University Press. 